\title{
KNOWLEDGE ON TEMPOROMANDIBULAR JOINT DISORDERS AMONG DENTISTS IN CHENNAI, TAMILNADU
}

\author{
K. Niraimathi', K. Ranjith², Vidya Albert Yen ${ }^{3}$, Edward Nijesh ${ }^{4}$, Shalini P5, Preetha E. Chaly6, Satheesh ${ }^{7}$, Sathyanarayanan ${ }^{8}$
}

${ }^{1}$ Associate Professor, Department of Dental Surgery, Chengalpattu Government Medical College.

${ }^{2}$ Senior Lecturer, Department of Public Health Dentistry, Asan Memorial Dental College.

${ }_{3}^{3}$ Associate Professor, Department of Dental Surgery, Chengalpattu Government Medical College.

${ }^{4}$ Reader, Department of Public Health Dentistry, Meenakshi Ammal Dental College.

5 Senior Lecturer, Department of Public Health Dentistry, Meenakshi Ammal Dental College.

${ }^{6}$ Professor \& HOD, Department of Public Health Dentistry, Meenakshi Ammal Dental College.

${ }^{7}$ Reader, Department of OMFS, Asan Memorial Dental College.

${ }^{8}$ Professor \& HOD, Department of OMFS, Asan Memorial Dental College.

\section{ABSTRACT}

\section{BACKGROUND}

Temporomandibular Joint Disorder (TMD) is one of the most common problem in dentistry. TMD problems hamper the day-to-day activities of the affected individuals. Even though TMD problems cause immense compromises in the quality of lives of the affected individuals, the knowledge regarding these TMD problems among dentists are less prevalent.

The aim of the study was to assess the knowledge regarding aetiology, signs, symptoms, diagnosis and treatments for TMD problems among dentists in Chennai.

\section{MATERIALS AND METHODS}

A cross-sectional survey was conducted among 268 general dental practitioners and specialists in Chennai. A questionnaire consisting of 20 questions regarding aetiology, signs, symptoms, diagnosis and treatment of TMD problems was used to assess the knowledge of the dentists. The responses were coded and subjected to statistical analysis using SPSS 17.0 software. A compari son between level of knowledge among General dentists and Specialist using Chi-square test was done.

\section{RESULTS}

The study population comprised of 131 (49\%) general dental practitioners and 137 (51\%) specialists. The results showed that the TMD specialists had significantly more knowledge than the general dental practitioners $(\mathrm{P}<0.15)$. Only about 11 (8.4\%) of GDPs and $6(4.4 \%)$ of specialists had low level of knowledge. 80 (61.1\%) of GDPs and 74 (54\%) of specialists had relatively low knowledge. Fair level of knowledge was observed in 40 (30.5\%) of GDPs and 56 (40.9\%) of specialists.

\section{CONCLUSION}

The study revealed that specialists in TMD were more knowledgeable than general dentists. With increasing experience, the knowledge of the dentists amplified. To increase the knowledge among general dentists, continued dental education programs coupled with scientific deliberations are necessary.

\section{KEYWORDS}

Temporomandibular Joint Disorder, Dentists, Aetiology, Knowledge.

HOW TO CITE THIS ARTICLE: Niraimathi K, Ranjith K, Yen VA, et al. Knowledge on temporomandibular joint disorders among dentists in Chennai, Tamilnadu. J. Evolution Med. Dent. Sci. 2016;5(99):7244-7251, DOI: 10.14260/jemds/2016/1639

\section{BACKGROUND}

Temporomandibular Joint Disorders (TMD) and their relevance to dentistry has been a highly debated topic in recent years. The Temporomandibular Joint (TMJ) syndrome was first described by Costen in 1934. Although Costen was not the first to ascribe ear pain, tinnitus, impaired hearing, and dizziness to TMJ dysfunction, he developed an integrated and systematic approach ascribing the symptoms to dental malocclusion. A few years after his original article, the term Costen's Syndrome came into general use.

Financial or Other, Competing Interest: None.

Submission 05-11-2016, Peer Review 28-11-2016,

Acceptance 05-12-2016, Published 12-12-2016.

Corresponding Author:

Dr. K. Ranjith,

\#13/4, K. K. St., Chinna Natham,

Chengalpattu-603002, Tamilnadu.

E-mail: drranjith84@gmail.com

DOI: $10.14260 /$ jemds/2016/1639
The American Dental Association President's Conference on Temporomandibular Disorders (American Dental Association, 1983) (Laskin et al., 1983) defined TMD as a group of orofacial disorders characterised by pain in the preauricular area, TMJ, or muscles of mastication, limitations and deviations in mandibular range of motion, TMJ sounds during jaw function. Luther (1998) used the term TMD to signify the variety of symptoms, signs and combinations thereof that have been assigned to the TMJ and its related structures. Thus, it becomes apparent that clinicians cannot agree upon a precise definition for TMD. Knowledge about Temporomandibular Joint Disorders has grown throughout the ages. In general, treatment philosophies have moved from a mechanistic dental approach to a biopsychosocial medical model, comparable to the treatment of other joint and muscle conditions in the body. Beneficial occlusal appliance therapy and TMJ disc-recapturing surgery were reported as early as the 1800s. During the same period, the understanding of the importance to harmonise the occlusion for the health of the 
masticatory muscles and TMJs developed as the skills to reconstruct natural teeth advanced. As enthusiasm grew for obtaining optimum health, comfort, and function, the popularity of equilibrating the natural dentition also developed. ${ }^{1}$

Temporomandibular Joint Disorders refer to a complex and poorly understood set of conditions, manifested by pain in the area of the jaw and associated muscles and limitations in the ability to make the normal movements of speech, facial expression, eating, chewing, and swallowing. Conditions that routinely affect other joints in the body, such as arthritis and trauma, also affect the Temporomandibular Joint.

Generally, Temporomandibular Joint Disorders account for the most common orofacial pains rising from musculoskeletal origin. Researchers generally agree that the most common temporomandibular diseases/disorders fall into three main categories. A person may have one or more of these conditions: Arthritis, such as osteoarthritis or rheumatoid arthritis in the jaw joint; Internal derangement of the joint, meaning the soft tissue disc which functions as a cushion between the skull and the jaw joint becomes displaced; Myofascial pain, discomfort or pain in the muscles that control jaw function and those in the neck and shoulders. ${ }^{2}$

The diagnosis of orofacial pain can be quite difficult and often presents a serious challenge to most practitioners. Having sufficient knowledge and skills regarding TMD helps the dentist in recognising any irregularities in the Temporomandibular joint during examination, and then, referring the patient to the appropriate professionals, thereby terminating the cycle of perpetual medical referrals. To assess the knowledge and beliefs of general dental practitioners regarding TMD, several studies have been carried out in different countries. In one study, there was a high degree of discrepancy in TMD aetiology, diagnosis, and treatment between general dental practitioners and specialists, which was an indication of dentists' lack of knowledge and up-to-date information regarding TMD. ${ }^{3}$

In general, TMD patients are not welcomed by practising dentists and they are usually referred to the orofacial pain clinics. However, it has been shown that a general dental practitioner could individually predict treatment outcome with similar results as a TMD specialist in selected patients diagnosed with TMD. Several studies have assessed dentists' knowledge of and attitude towards TMD in adults. Differences were found between general practice dentists (GPDs) and an expert group (Specialists) in assessment of TMD causes, diagnosis, and choice of therapy.

To bring the problem to the attention of the GPDs and dental schools, professional organisations have published recommendations on how to diagnose and treat children and adolescents with TMD. Many epidemiological studies have reported the prevalence of TMD pain in children and adolescents to vary between $2 \%$ and $7 \%$. As the symptoms of pain are common amongst youth, it has been recommended that routine dental examinations include a TMD evaluation. Different factors, such as knowledge, attitude, may be involved and determine what TMD care is provided. It is therefore important to assess these factors, so that recommendations regarding education can be made. This study was a part of a comprehensive project to determine dentists' knowledge of Temporomandibular joint Disorders. ${ }^{4}$

\section{MATERIALS AND METHODS}

A cross-sectional survey was carried out to evaluate the level of knowledge regarding TMD problems among dentists in Chennai.

The source of data was primary and was obtained through a questionnaire survey. The survey was conducted among the general dental practitioners and specialists employed in the private dental colleges in the Chennai.

The ethical clearance was obtained from the Institutional Review Board of Meenakshi Academy of Higher Education and Research, Chennai.

A pilot study was carried out to pre-test the questionnaire, check the feasibility of the study. A total of 50 dentists participated in the study. Following the pilot study, necessary corrections were done and the revised questionnaire was prepared for the survey.

Following the pilot study, using the ' $n$ ' master software version $1.0 @$ with the power of the study being set at $90 \%$, alpha error at $5 \%$, a sample size of 260 dentists were needed for the study.

Cluster sampling methodology was used. There are 11 private dental colleges in Chennai. From these clusters, private dental colleges were randomly selected one after the other. All the dentists who were employed in the selected private dental colleges formed the study population. In this study, 3 private dental colleges were randomly selected to reach through the required sample size population.

Data was collected by using self-designed questionnaire. The questionnaire was developed in English language. Each questionnaire contained two parts: the first part with basic demographic details of the participants, the second part dealt with the questions regarding knowledge of TMD problems. The questionnaire consisted of 20 closed ended questions which were taken from relevant textbooks and also approved by the specialists.5,6 The questions were divided into four groups. Each group contains five questions which consist of four domains that involve aetiology, sign and symptoms, diagnosis and treatment.

Self-administrated questionnaire was given to the 268 dentists. The questionnaire was explained in order to avoid any ambiguity. They were assured of the confidentiality of their responses and were requested to give appropriate answers. The filled questionnaires were collect on the same day. After collecting the completed questionnaires, the correct answers were scored accordingly and zero was given for every incorrect answers. The final score was calculated by summing up the obtained responses. To evaluate the level of knowledge, the following interpretation was used.

- Score of 1-6: low level of knowledge.

- Score of 7-12: relatively low level of knowledge.

- $\quad$ Score of 13-18: fair level of knowledge.

- $\quad$ Score of 19 and up: high level of knowledge. 5

The resulting data was coded and statistical analysis was done using SPSS (Statistical Package for Social Sciences) version 17.0 software. In the present study, frequency and percentage was calculated, along with mean and standard deviation; $\mathrm{p}$-value was fixed at $<0.05$. A comparison between level of knowledge among General dentists and Specialists using Chi-square test was done. 


\section{RESULTS}

\section{Demographic Features of the Study Population according} to Sex and Qualification

The study population was of 268 dentists, 131 (49\%) were general dental practitioners and 137 (51\%) specialists. Mean age of study subjects was 31.16 with 158 (59\%) males and 110 (41\%) females. Based on the years of experience in clinical practice, $228(75.2 \%)$ participants had 1-10 years of practice, $37(13.8 \%)$ of the participants had 11-20 years of clinical practice and $2(7 \%)$ participants had 21-30 years of clinical practice and about $1(4 \%)$ participant had 31-40 years of clinical practice. (Table 1).

\section{Distributions of the Study Population's Knowledge on Aetiology of Temporomandibular joint Disorders among Dentists}

Result reveals that $56.5 \%$ General dental practitioners (GDPs) and $60.6 \%$ Dental specialists said that behavioural factor as a direct contributing factor of Temporomandibular Joint pain, 7.6\% GDPs and $11.7 \%$ dental specialists said that social factor as a direct contributing factor of Temporomandibular Joint pain, $6.9 \%$ GDPs and $14.6 \%$ dental specialists said that cognitive factor as a direct contributing factor of Temporomandibular Joint pain, 29\% GDPs and 13.1\% dental specialists said that emotional factor as a direct contributing factor of Temporomandibular Joint pain. The difference noted was not statistically significant $(\mathrm{P}>0.05)$.

In the present study, $2.3 \%$ GDPs and $5.2 \%$ dental specialists said that resultant muscle fatigue is a most common cause for musculoskeletal pain, 13.8\% GDPs and 11.6\% dental specialists said that Trauma is a most common cause for musculoskeletal pain, $19.8 \%$ GDPs and $11.6 \%$ dental specialists said that muscle strain is a most common cause for musculoskeletal pain, $64.1 \%$ GDPs and $71.6 \%$ dental specialists said that resultant muscle fatigue, trauma, muscle strain are the most common causes for musculoskeletal pain . The difference noted was not statistically significant $(\mathrm{P}>0.05)$.

About $67.9 \%$ GDPs and $65.7 \%$ dental specialists said that trauma was a common cause for Temporomandibular Joint ankylosis, 9.2\% GDPs and 5.1\% dental specialists said that inflammation was a common cause for Temporomandibular Joint ankylosis, 3.9\% GDPs and 6.6\% dental specialists said that neoplasia was a common cause for Temporomandibular Joint ankylosis, 19\% GDPs and 22.6\% dental specialists said Trauma, Inflammation, Neoplasia were common causes for Temporomandibular Joint ankylosis. The difference noted was not statistically significant $(\mathrm{P}>0.05)$.

In the present study, $64.6 \%$ GDPs and $69.3 \%$ dental specialists said that more women experience Temporomandibular Joint Disorder than men, 35.4\% GDPs and $30.7 \%$ dental specialists disagreed that more women experience Temporomandibular Joint Disorder than men. The difference noted was not statistically significant $(\mathrm{P}>0.05)$.

In the present study, $48.9 \%$ GDPs and $47.5 \%$ dental specialists said that Temporomandibular Joint Disorder is seen most commonly in people between the age groups of 2040 years, $21.3 \%$ GDPs and $24.8 \%$ dental specialists said that Temporomandibular Joint Disorder is seen most commonly in people between the age groups of 40-60 years. 28.2\% GDPs and $24.8 \%$ dental specialists said that Temporomandibular Joint Disorder is seen most commonly in people between 20 40 and $40-60$ age groups. $1.6 \%$ GDPs and $2.9 \%$ dental specialists responded said that Temporomandibular Joint Disorder is seen most commonly in people between the age groups of none of the above mentioned years. The difference noted was statistically significant $(\mathrm{P}>0.05)$. (Table 2$)$.

Distributions of the Study Population's Knowledge on Sign and Symptoms of Temporomandibular Joint Disorders among Dentists

Among the study subjects, $17.2 \%$ GDPs and $13.9 \%$ dental specialists agreed that Patients with Temporomandibular Joint arthropathy often have a history of bothersome episodes like Popping, Clicking. 7.5\% GDPs and 5.1\% dental specialists agreed that Patients with Temporomandibular Joint arthropathy often have a history of bothersome episodes like Grafting, Locking. 20.1\% GDPs and 20.4\% dental specialists agreed that Patients with Temporomandibular Joint arthropathy often have a history of bothersome like pain upon joint motion. 58.6\% GDPs and $60.6 \%$ dental specialists agreed that Patients with Temporomandibular Joint arthropathy often have a history of bothersome episodes like Popping, Clicking, Grating, Locking, Pain upon joint motion. The difference noted was not statistically significant $(\mathrm{P}>0.05)$.

Among the study subjects $61 \%$ GDPs and $53.3 \%$ dental specialists agreed that most common clinical sign found in Temporomandibular Joint dysfunction syndrome is Pain, anterior to ear, usually unilateral, extending anteriorly in the face, especially increased by use of the joint. 13\% GDPs and $21.1 \%$ of dental specialists agreed that most common clinical sign found in Temporomandibular Joint dysfunction syndrome is pain in the temporal or cervical area, usually associated with facial pain. $21.3 \%$ GDPs and 19\% dental specialists agreed that most common clinical sign found in Temporomandibular Joint dysfunction syndrome is Inability to open the mouth normally without pain. $4.7 \%$ GDPs and 6.6 $\%$ dental specialists agreed that most common clinical sign found in Temporomandibular Joint dysfunction syndrome is none of the above. The difference noted was not statistically significant $(\mathrm{P}>0.05)$.

In the present study, $65.7 \%$ GDPs and $66.4 \%$ dental specialists agreed that TMJ arthropathy is the TMJ internal derangement which is characterised by a progressive anterior disk displacement relative to the condyle, $34.3 \%$ and $33.6 \%$ dental specialists did not agree that TMJ arthropathy is the TMJ internal derangement which is characterised by a progressive anterior disk displacement relative to the condyle. The difference noted was statistically significant $(\mathrm{P}<0.05)$.

Among the study subjects, 9.7\% GDPs and $9.4 \%$ dental specialists said that following presenting sign of Temporomandibular Joint Disorder is Not true for Joint clicking. 16\% GDPs and 8\% dental specialists answered that following presenting sign of Temporomandibular Joint Disorder is not true for Limited mouth opening. 12.7\% GDPs and $17.6 \%$ dental specialists answered that following presenting sign of Temporomandibular Joint Disorder is Not true for Masseter muscle pain. 48.5\% GDPs and $46.7 \%$ dental specialists answered that following presenting sign of Temporomandibular Joint Disorder is Not true for Pain in the cervical region. The difference noted was not statistically significant $(\mathrm{P}>0.05)$.

Among the study subjects, $23.5 \%$ GDPs and $21.6 \%$ dental specialists said that Synovial chondromatosis is characterised by Inflammation of synovial membrane. 17.2\% GDPs and 
$17.6 \%$ dental specialists said that Synovial chondromatosis is characterised by Rupture of synovial membrane, 48.5\% GDPs and $46.7 \%$ dental specialists said that Synovial chondromatosis is characterised by Cartilaginous nodules of the synovial membrane. $10.8 \%$ GDPs and $14.1 \%$ dental specialists said that Synovial chondromatosis is characterised by none of the above. The difference noted was not statistically significant $(\mathrm{P}>0.05)$. (Table 3 ).

\section{Distributions of the Study Population's Knowledge on Diagnosis of Temporomandibular joint Disorders among Dentists}

In the present study, $44.4 \%$ GDPs and $40.8 \%$ dental specialists responded that the following procedures mentioned below are the proposed investigation procedures for the temporomandibular disorders except Ultrasonography examination. $32.5 \%$ GDPs and $36.5 \%$ dental specialists responded that the following procedures mentioned below are the proposed investigation procedures for the temporomandibular disorders except Plain radiography. 7.8\% GDPs and 8.8\% dental specialists responded that the following procedures mentioned below are the proposed investigation procedures for the Temporomandibular disorders except Magnetic resonance imaging. 15.3\% GDPs and 13.9\% dental specialists responded that the following procedures mentioned below are the proposed investigation procedures for the temporomandibular disorders except temporomandibular arthroscopy. The difference noted was not statistically significant $(\mathrm{P}>0.05)$.

Among the study subjects, $51.9 \%$ GDPs and $49.6 \%$ dental specialists said that isotope used for nuclear imaging for Temporomandibular Joint as Technetium 99. 21.2\% GDPs and $22.9 \%$ dental specialists said that isotope used for nuclear imaging for Temporomandibular Joint as iodine 131. 12.1\% GDPs and $12.6 \%$ dental specialists said that isotope used for nuclear imaging for Temporomandibular Joint as cobalt. 6.14\% GDPs and $15.1 \%$ dental specialists said that isotope used for nuclear imaging for Temporomandibular Joint as Technetium 98. The difference noted was not statistically significant $(\mathrm{P}>0.05)$.

Among the study subjects, 9.9\% GDPs and 8\% dental specialists responded that Temporomandibular Joint Disorder diagnosis can be confirmed through OPG. 27.5\% GDPs and $11.7 \%$ dental specialists responded that Temporomandibular Joint Disorder diagnosis can be confirmed through TMJ Tomography. $10.8 \%$ GDPs and $11.7 \%$ dental specialists responded that Temporomandibular Joint Disorder diagnosis can be confirmed through Dynamic MRI. 51.8\% GDPs and $68.6 \%$ dental specialists responded that Temporomandibular Joint Disorder diagnosis can be confirmed through OPG, TMJ Tomography, dynamic MRI. The difference noted was not statistically significant $(\mathrm{P}>0.05)$.

In the present study, 52.4\% GDPs and $41.6 \%$ dental specialists responded that in Temporomandibular Joint Disorder Imaging, the TMJ Tomogram exceeds the capacity of the transcranial radiograph in providing information to be "as Surface changes" of the condyle, fossa, or eminence in the medial-lateral dimensions. 21\% GDPs and 24.8\% dental specialists responded that in Temporomandibular Joint Disorder Imaging, the TMJ Tomogram exceeds the capacity of the transcranial radiograph in providing information to be "No radiographic changes". 19\% GDPs and 24\% dental specialists responded that in Temporomandibular Joint Disorder Imaging, the TMJ Tomogram exceeds the capacity of the transcranial radiograph in providing information to be "Soft tissue changes". 7.6\% GDPs and 9.6\% dental specialists responded that in Temporomandibular Joint Disorder Imaging, the TMJ Tomogram exceeds the capacity of the transcranial radiograph in providing information to be "none of the above". The difference noted was not statistically significant $(\mathrm{P}>0.05)$

Among the study subjects, $41.8 \%$ GDPs and $40.8 \%$ dental specialists said that in TMJ affected by Rheumatic disease, radiographic changes were noted to be decreased joint spaces. 29.4\% GDPs and $27.7 \%$ dental specialists said that in TMJ affected by Rheumatic disease, radiographic changes were noted to be increased joint spaces. 23.1\% GDPs and 17.4\% dental specialists said that in TMJ affected by Rheumatic disease, radiographic changes were noted to be no radiographic changes. 5.7\% GDPs and $13.4 \%$ dental specialists said that in TMJ affected by Rheumatic disease, radiographic changes were noted to be none of the above. The difference noted was statistically significant $(\mathrm{P}>0.05)$. (Table 4$)$.

\section{Distributions of the Study Population's Knowledge on Treatment of Temporomandibular joint Disorders among Dentists}

In the present study, $11.5 \%$ GDPs and $10.2 \%$ dental specialists responded that Non-Narcotic analgesics as medicaments used for Temporomandibular Joint pain. 27.5\% GDPs and 27.7\% dental specialists agreed that Narcotic analgesic medicaments can be used for Temporomandibular Joint pain. 9.1\% GDPs and $13.1 \%$ dental specialists agreed that muscle relaxants as medicaments used for Temporomandibular Joint pain. 51.9\% GDPs and $48.9 \%$ dental specialists responded that NonNarcotic analgesics, Narcotic analgesics, Muscle Relaxants as medicaments used for Temporomandibular Joint pain. The difference noted was not statistically significant $(\mathrm{P}>0.05)$.

Among the study subjects, $10.7 \%$ GDPs and $9.5 \%$ dental specialists responded that for TMJ clicking, Dautrey procedure is a treatment modality. $34.3 \%$ GDPs and $45.2 \%$ dental specialists responded that for TMJ dislocation, Dautrey procedure is a treatment modality. 19\% GDPs and 54.7\% dental specialists responded that for TMJ ankylosis, Dautrey procedure is a treatment modality. 35.8\% GDPs and $29.2 \%$ of dental specialists responded that for TMJ clicking, TMJ dislocation, TMJ ankylosis, Dautrey procedure is a treatment modality for TMD.

Among the study subjects, 5.3\% GDPs and 2.9\% dental specialists responded that Patients education as the pain management in Temporomandibular Joint disorder. 10.7\% GDPs and 9.5\% dental specialists responded that alleviating the causative factors as the pain management in Temporomandibular Joint disorder. 19\% GDPs and 9.5\% dental specialists responded analgesics as the pain management in Temporomandibular Joint disorder. 65\% GDPs and 78.1\% dental specialists responded all of the above for pain management in Temporomandibular Joint disorder. The difference noted was not statistically significant $(\mathrm{P}>0.05)$.

Among the study subjects, $8.2 \%$ GDPs and $8 \%$ dental specialists responded that Reassurance and counselling as appropriate in the management of temporomandibular disorders. $11.6 \%$ GDPs and $6.6 \%$ dental specialists responded that NSAID drug therapy as appropriate in the management of 
temporomandibular disorders. 9\% GDPs and 5.1\% dental specialists responded that Splint therapy is appropriate in the management of temporomandibular disorders. 71.3\% GDPs and $80.3 \%$ dental specialists responded all of the above as appropriate in the management of temporomandibular disorders. The difference noted was not statistically significant $(\mathrm{P}>0.05)$.

In response to the last question of the questionnaire, asking the subjects about the sources they were willing to gain relevant knowledge of TMD, the specialists were mostly, willing to use the internet. Also, they update through reading the journals and attending CME programs. The difference noted was statistically significant $(\mathrm{P}>0.05)$. (Table 5).

Distributions of the Study Population on Domains, Correct Answers in Temporomandibular Joint Disorders among Dentists.

In the present study $60 \%$ GDPs and $66 \%$ Specialists had given correct respondents on aetiology domains the difference noted was not statistically significant $(\mathrm{P}>0.05)$.

$59 \%$ GDPs and $61 \%$ Specialists had given correct respondents on signs and symptoms domain. The difference noted was not statistically significant $(\mathrm{P}>0.05)$. 48\% GDPs and $50 \%$ Specialist had given correct respondents on diagnosis domain. The difference noted was not statistically significant ( $P>0.05$ ). 54\% GDPs and 74\% Specialists had given correct respondents on treatment domain. The difference noted was statistically significant $(\mathrm{P}<0.05)$.
Responses of the Study Subjects Based on the Levels of Knowledge on Temporomandibular Joint Disorders.

Mean knowledge score of all participants was 11.35 and it was relatively at low level (Of a total of 20 achievable scores). 8.4\% GDPs and 4.4\% Specialists were rated as having a low level of TMD knowledge, 61.1\% GDPs and 54\% Specialists were rated as having a relatively low level of TMD knowledge, and 30.5\% GDPs and $40.9 \%$ Specialists were rated as having a fair level of knowledge towards TMD. $0.4 \%$ Specialists were rated as having a high level of TMD knowledge. (Table 7).

\begin{tabular}{|c|c|}
\hline Variables & $\begin{array}{c}\text { Total Number- } \\
\mathbf{2 6 8}(\mathbf{6})\end{array}$ \\
\hline Gender & $158(59 \%)$ \\
\hline Male & $110(41 \%)$ \\
\hline Female & $131(49 \%)$ \\
\hline Occupation & $137(51 \%)$ \\
\hline $\begin{array}{c}\text { General Dental } \\
\text { Practitioners }\end{array}$ & \\
\hline Specialist & $228(75.2 \%)$ \\
\hline $\begin{array}{c}\text { No. of Years in } \\
\text { Clinical Practice }\end{array}$ & $37(13.8 \%)$ \\
\hline 1-10 Years & $2(7 \%)$ \\
\hline 11-20 Years & $1(4 \%)$ \\
\hline 21-30 Years & 31-40 Years \\
\hline Table 1. Demographic Details of the Participants \\
\hline
\end{tabular}

\begin{tabular}{|c|c|c|c|c|}
\hline $\begin{array}{l}\text { Sl. } \\
\text { No. }\end{array}$ & Questions & $\begin{array}{c}\text { GDPs } \\
\text { N-131(\%) }\end{array}$ & $\begin{array}{c}\text { Dental Specialists } \\
\quad \mathrm{N}-137(\%)\end{array}$ & $\begin{array}{c}\text { p- } \\
\text { value }\end{array}$ \\
\hline \multirow{5}{*}{1} & $\begin{array}{l}\text { Which of the following can be termed as direct } \\
\text { contributing factors of Temporomandibular Joint pain }\end{array}$ & & & \multirow{5}{*}{.461} \\
\hline & a) Behavioural factor & $74(56.5 \%)$ & $83(60.6 \%)$ & \\
\hline & b) Social factor & $10(7.6 \%)$ & $16(11.7 \%)$ & \\
\hline & c) Cognitive factor & $9(6.9 \%)$ & $20(14.6 \%)$ & \\
\hline & d) Emotional factor & $38(29 \%)$ & $18(13.1 \%)$ & \\
\hline \multirow{5}{*}{2} & $\begin{array}{l}\text { Which of the following are the most } \\
\text { common causes of musculoskeletal pain }\end{array}$ & & & \multirow{5}{*}{1.68} \\
\hline & a) Resultant muscle fatigue & $3(2.3 \%)$ & $7(5.2 \%)$ & \\
\hline & b) Trauma & $18(13.8 \%)$ & $16(11.6 \%)$ & \\
\hline & c) Muscle strain & $26(19.8 \%)$ & $16(11.6 \%)$ & \\
\hline & d) All of the above & $84(64.1 \%)$ & $98(71.6 \%)$ & \\
\hline \multirow{5}{*}{3} & $\begin{array}{l}\text { Which according to you is the most common cause } \\
\text { for Temporomandibular Joint ankylosis? }\end{array}$ & & & \multirow{5}{*}{1.02} \\
\hline & a) Trauma & $89(67.9 \%)$ & $90(65.7 \%)$ & \\
\hline & b) Inflammation & $12(9.2 \%)$ & $7(5.1 \%)$ & \\
\hline & c) Neoplasia & $5(3.9 \%)$ & $9(6.6 \%)$ & \\
\hline & d) All of the above & $25(19 \%)$ & $31(22.6 \%)$ & \\
\hline \multirow{3}{*}{4} & $\begin{array}{l}\text { More women experience Temporomandibular } \\
\text { Joint Disorder than men. }\end{array}$ & & & \multirow{3}{*}{.826} \\
\hline & a) Yes & $81(64.6 \%)$ & $95(69.3 \%)$ & \\
\hline & b)No & $50(35.4 \%)$ & $42(30.7 \%)$ & \\
\hline \multirow{5}{*}{5} & $\begin{array}{l}\text { Temporomandibular Joint Disorder is seen most } \\
\text { commonly in people between the age groups of }\end{array}$ & & & \multirow{5}{*}{.053} \\
\hline & a) $20-40$ & $64(48.9 \%)$ & $65(47.5 \%)$ & \\
\hline & b) $40-60$ & $28(21.3 \%)$ & $34(24.8 \%)$ & \\
\hline & c) Both A and B & $37(28.2 \%)$ & $34(24.8 \%)$ & \\
\hline & d) None of the Above & $2(1.6 \%)$ & $4(2.9 \%)$ & \\
\hline
\end{tabular}




\begin{tabular}{|c|c|c|c|c|}
\hline $\begin{array}{l}\text { Sl. } \\
\text { No. }\end{array}$ & Questions & $\begin{array}{c}\text { GDPs } \\
\text { N-131 (\%) }\end{array}$ & $\begin{array}{c}\text { Dental Specialist } \\
\mathrm{N}-137(\%)\end{array}$ & p-value \\
\hline \multirow{5}{*}{6} & $\begin{array}{l}\text { Patients with Temporomandibular Joint } \\
\text { arthropathy often have a history of bothersome }\end{array}$ & & & \multirow{5}{*}{.461} \\
\hline & a) Popping, Clicking & $27(17.2 \%)$ & $19(13.8 \%)$ & \\
\hline & b) Grating, Locking & $13(7.5 \%)$ & $7(5.1 \%)$ & \\
\hline & c) Pain upon joint motion & $17(20.1 \%)$ & $28(20.4 \%)$ & \\
\hline & d) All of the above & $74(58.6 \%)$ & $83(60.7 \%)$ & \\
\hline \multirow{5}{*}{7} & $\begin{array}{l}\text { The most common clinical sign found in } \\
\text { Temporomandibular Joint dysfunction syndrome is }\end{array}$ & & & \multirow{5}{*}{1.65} \\
\hline & $\begin{array}{l}\text { a) Pain anterior to ear, usually unilateral, } \\
\text { extending anteriorly in the face, especially } \\
\text { increased by use of the joint }\end{array}$ & $80(61 \%)$ & $73(53.3 \%)$ & \\
\hline & $\begin{array}{l}\text { b) Pain in the temporal or cervical area, } \\
\text { usually associated with facial pain }\end{array}$ & $17(13 \%)$ & $29(21.1 \%)$ & \\
\hline & $\begin{array}{l}\text { c) Inability to open the mouth } \\
\text { normally without pain }\end{array}$ & $28(21.3 \%)$ & $26(19 \%)$ & \\
\hline & d) None of the above & $6(4.7 \%)$ & $9(6.6 \%)$ & \\
\hline \multirow[t]{3}{*}{8} & $\begin{array}{c}\text { TMJ arthropathy is the TMJ internal derangement } \\
\text { which is characterised by a progressive anterior } \\
\text { disk displacement } \\
\text { relative to the condyle. }\end{array}$ & & & \multirow[t]{3}{*}{070} \\
\hline & a) Agree & $85(65.7 \%)$ & $91(66.4 \%)$ & \\
\hline & b) Disagree & $46(34.3 \%)$ & $46(33.6 \%)$ & \\
\hline \multirow{5}{*}{9} & $\begin{array}{l}\text { Which of the following presenting sign of } \\
\text { Temporomandibular Joint Disorder is NOT true? }\end{array}$ & & & \multirow{5}{*}{.172} \\
\hline & a) Joint clicking & $13(9.7 \%)$ & $13(9.4 \%)$ & \\
\hline & b) Limited mouth opening & $23(12.7 \%)$ & $11(8 \%)$ & \\
\hline & c) Masseter muscle pain & $16(16.0 \%)$ & $27(20 \%)$ & \\
\hline & d) Pain in the cervical region & $79(61.6 \%)$ & $86(62.6 \%)$ & \\
\hline \multirow{5}{*}{10} & Synovial chondromatosis is characterised by & & & \multirow{5}{*}{.359} \\
\hline & a) Inflammation of synovial membrane & $34(23.5 \%)$ & $29(21.6 \%)$ & \\
\hline & b) Rupture of synovial membrane & $22(17.2 \%)$ & $24(17.6 \%)$ & \\
\hline & c) Cartilaginous nodules of the synovial membrane & $66(48.5 \%)$ & $64(46.7 \%)$ & \\
\hline & d) None of the above & $9(10.8 \%)$ & $20(14.1 \%)$ & \\
\hline
\end{tabular}

\begin{tabular}{|c|c|c|c|c|}
\hline $\begin{array}{l}\text { Sl. } \\
\text { No. }\end{array}$ & Questions & $\begin{array}{c}\text { GDPs } \\
\text { N-131 (\%) } \\
\end{array}$ & $\begin{array}{c}\text { Dental specialists } \\
\mathrm{N}-137(\%)\end{array}$ & $\begin{array}{c}\text { p- } \\
\text { value }\end{array}$ \\
\hline \multirow{5}{*}{11} & $\begin{array}{l}\text { The following are the proposed investigation procedures } \\
\text { for the Temporomandibular disorders except }\end{array}$ & & & \multirow{5}{*}{1.40} \\
\hline & a) Ultrasonography examination & $63(44.4 \%)$ & $56(40.8 \%)$ & \\
\hline & b) Plain radiography of the Temporomandibular Joint. & $37(32.5 \%)$ & $50(36.5 \%)$ & \\
\hline & c) Magnetic resonance imaging & $9(7.8 \%)$ & $12(8.8 \%)$ & \\
\hline & d) Temporomandibular arthroscopy & $22(15.3 \%)$ & $19(13.9 \%)$ & \\
\hline \multirow{5}{*}{12} & The isotope used for nuclear imaging for Temporomandibular Joint is: & & & \multirow{5}{*}{.557} \\
\hline & a) Technetium 99 & $71(51.9 \%)$ & $68(49.6 \%)$ & \\
\hline & b) Iodine 131 & $26(21.2 \%)$ & $30(22.9 \%)$ & \\
\hline & c) Cobalt 60 & $15(12.1 \%)$ & $17(12.4 \%)$ & \\
\hline & d) Technetium 98 & $17(14 \%)$ & $20(15.1 \%)$ & \\
\hline \multirow{5}{*}{13} & Temporomandibular Joint Disorder diagnosis can be confirmed through & & & \multirow{5}{*}{7.78} \\
\hline & a) OPG & $13(9.9 \%)$ & $11(8 \%)$ & \\
\hline & b) TMJ Tomography & $36(27.5 \%)$ & $16(11.7 \%)$ & \\
\hline & c) Dynamic MRI & $14(10.8 \%)$ & $16(11.7 \%)$ & \\
\hline & d) All of the above & $68(51.8 \%)$ & $94(68.6 \%)$ & \\
\hline 14 & $\begin{array}{l}\text { In Temporomandibular Joint Disorder Imaging, the TMJ } \\
\text { Tomogram exceeds the capacity of the transcranial } \\
\text { radiograph in providing information to be }\end{array}$ & & & 3.28 \\
\hline
\end{tabular}




\begin{tabular}{|c|c|c|c|c|}
\hline & $\begin{array}{l}\text { a) Surface changes of the condyle, fossa, or } \\
\text { eminence in the medial-lateral dimensions }\end{array}$ & $69(52.4 \%)$ & $57(41.6 \%)$ & \\
\hline & b) No radiographic changes & $27(21 \%)$ & $34(24.8 \%)$ & \\
\hline & c) Soft tissue changes & $25(19 \%)$ & $33(24 \%)$ & \\
\hline & d) None of the above & $10(7.6 \%)$ & $13(9.6 \%)$ & \\
\hline \multirow{5}{*}{15} & In TMJ affected by Rheumatic disease, radiographic changes noted is & & & \multirow{5}{*}{.034} \\
\hline & a) Decreased joint space & $55(41.8 \%)$ & $56(40.8 \%)$ & \\
\hline & b) Increased joint space & $37(29.4 \%)$ & $38(27.7 \%)$ & \\
\hline & c) No Radiographic changes & $29(23.1 \%)$ & $24(17.4 \%)$ & \\
\hline & d) None of the above & $7(5.7 \%)$ & $18(13.4 \%)$ & \\
\hline
\end{tabular}

\begin{tabular}{|c|c|c|c|c|}
\hline $\begin{array}{l}\text { Sl. } \\
\text { No. }\end{array}$ & Question & $\begin{array}{c}\text { GDPs } \\
\mathrm{N}-131(\%)\end{array}$ & $\begin{array}{c}\text { Dental specialist } \\
\mathrm{N}-137(\%)\end{array}$ & $\begin{array}{c}\text { p- } \\
\text { value }\end{array}$ \\
\hline \multirow{5}{*}{16} & $\begin{array}{l}\text { Which of the following are medicaments used } \\
\text { for Temporomandibular Joint pain. }\end{array}$ & & & \multirow{5}{*}{.241} \\
\hline & a) Non-Narcotic Analgesics & $15(11.5 \%)$ & $14(10.2 \%)$ & \\
\hline & b) Narcotic Analgesics & $12(9.1 \%)$ & $18(13.1 \%)$ & \\
\hline & c) Muscle Relaxant & $36(27.5 \%)$ & $38(27.7 \%)$ & \\
\hline & d) All of the Above & $68(51.9 \%)$ & $67(48.9 \%)$ & \\
\hline \multirow{5}{*}{17} & $\begin{array}{c}\text { Dautrey procedure is a treatment modality for } \\
\text { which of the following temporomandibular disorder. }\end{array}$ & & & \multirow{5}{*}{3.3} \\
\hline & a) TMJ clicking & $14(10.7 \%)$ & $13(9.5 \%)$ & \\
\hline & b) TMJ dislocation & $45(34.3 \%)$ & $62(45.2 \%)$ & \\
\hline & c) TMJ ankylosis & $25(19 \%)$ & $22(16.1 \%)$ & \\
\hline & d) All of the above & $47(35.8 \%)$ & $40(29.2 \%)$ & \\
\hline \multirow{5}{*}{18} & Pain management in Temporomandibular Joint Disorder is by & & & \multirow{5}{*}{3.5} \\
\hline & a) Patients education & $7(5.3 \%)$ & $4(2.9 \%)$ & \\
\hline & b) Alleviating the causative factors & $14(10.7 \%)$ & $13(9.5 \%)$ & \\
\hline & c) Analgesics & $21(19 \%)$ & $13(9.5 \%)$ & \\
\hline & d) All of the above & $89(65 \%)$ & $107(78.1 \%)$ & \\
\hline \multirow[t]{5}{*}{19} & $\begin{array}{l}\text { The following methods are appropriate in the } \\
\text { management of Temporomandibular disorders }\end{array}$ & & & 11.1 \\
\hline & a) Reassurance and counselling & $11(8.2 \%)$ & $11(8 \%)$ & \\
\hline & b) NSAID drug therapy & $22(11.6 \%)$ & $9(6.6 \%)$ & \\
\hline & c) Splint therapy & $17(9 \%)$ & $7(5.1 \%)$ & \\
\hline & d) All of the above & $81(71.3 \%)$ & $110(80.3 \%)$ & \\
\hline \multirow[t]{5}{*}{20} & $\begin{array}{l}\text { How do you update your knowledge on treatment } \\
\text { of Temporomandibular joint disorder? }\end{array}$ & & & .001 \\
\hline & a) Internet & $33(26.1 \%)$ & $19(13.8 \%)$ & \\
\hline & b) Journals & $16(12.2 \%)$ & $7(5.1 \%)$ & \\
\hline & c) CME programs & $11(8.3 \%)$ & $9(6.6 \%)$ & \\
\hline & d) All of the above & $70(53.4 \%)$ & $102(74.5 \%)$ & \\
\hline & Table 5. Distribution of the Knowledge of the Tr & f the Study & cipants & \\
\hline
\end{tabular}

\begin{tabular}{|c|c|c|c|}
\hline Domains & $\begin{array}{l}\text { GDPs } \\
\text { (\%) }\end{array}$ & $\begin{array}{c}\text { Specialists } \\
\text { (\%) }\end{array}$ & $\begin{array}{c}\text { P- } \\
\text { value }\end{array}$ \\
\hline Aetiology & $60 \%$ & $66 \%$ & 0.520 \\
\hline $\begin{array}{l}\text { Signs and } \\
\text { Symptoms }\end{array}$ & $59 \%$ & $61 \%$ & 0.280 \\
\hline Diagnosis & $48 \%$ & $50 \%$ & 0.511 \\
\hline Treatment & $54 \%$ & $74 \%$ & 0.033 \\
\hline \multicolumn{4}{|c|}{$\begin{array}{l}\text { Table 6. Distributions of the Study Population } \\
\text { on Domains, Correct responses Towards } \\
\text { Knowledge of TMD Problems among Dentists }\end{array}$} \\
\hline
\end{tabular}

\begin{tabular}{|c|c|c|c|}
\hline Score & $\begin{array}{c}\text { GDPs } \\
131(\%)\end{array}$ & $\begin{array}{c}\text { Specialist } \\
137(\%)\end{array}$ & P-value \\
\hline Low & $11(8.4 \%)$ & $6(4.4 \%)$ & \multirow{5}{*}{0.155} \\
\hline Relatively low & $80(61.1 \%)$ & $74(54 \%)$ & \\
\hline Fair & $40(30.5 \%)$ & $56(40.9 \%)$ & \\
\hline High & $0(0 \%)$ & $1(0.7 \%)$ & \\
\hline Total & 100.0 & & \\
\hline \multicolumn{4}{|c|}{$\begin{array}{l}\text { Table 7. Showing the Levels of } \\
\text { the Knowledge among Dentists }\end{array}$} \\
\hline
\end{tabular}




\section{DISCUSSION}

In the present study, the majority of the dentists have relatively low level of knowledge towards temporomandibular joint disorders.

In our study, specialists showed a higher level of knowledge on domains about aetiology, signs and symptoms, diagnosis and treatment than general dentists. In these domains, only treatments domain had showed statistically significance $(\mathrm{P}=0.033) .74 \%$ specialists had better treatment domain knowledge than general dentists, they may be updating their knowledge through books and attending CME programs which is also similar to the study conducted by Maryam Bharvand et al. Nearly $80 \%$ of specialists considered reference books as their source of obtaining information regarding TMD. In addition, one-third of specialists regarded the internet as their primary source of information. This can be the reason for the higher level of knowledge among specialists, since the information gained from the internet can be more up-to-date than that acquired from the reference books. General dentists noted that during the undergraduate years, the majority of dentists mostly receive courses focusing on the signs and symptoms, diagnosis, and treatment of TMD, paying less attention to the underlying TMD problems. Furthermore, lack of encounter with TMD patients by dental students during their education has led to lack of practice and knowledge regarding the TMD Problems. The same trend is present even during practice when confronting a TMD case, where the dentist does not put enough effort into looking for the underlying cause and makes a diagnosis on the sight of the first sign and symptom, leading to a treatment that only relieves the pain and discomfort in the least amount of time possible. ${ }^{3}$ Similarly, this study concluded that the participating dentists had more knowledge regarding aetiologic factors, in domains of pathophysiology, diagnosis, and treatment. The findings of the present study partially replicate the results, although in that study, the participating dentists showed a desirable level of knowledge regarding TMD, rarely were they willing to visit TMD patients. There was a high consensus in TMD knowledge among the specialists and a high degree of agreement found between general practitioners and TMD specialists in another study, Tegelberg study in Sweden assessing the dentists' knowledge of TMJ disorders in children and adolescents. In some areas; however, TMD specialists still needed to reach a consensus. In $65 \%$ of statements, differences in knowledge between general practitioners and TMD specialists were not significant; but in the domain of treatment and prognosis, the differences were significant. Most of these statements were related to morphological factors. ${ }^{7}$

In the present study, nearly $8.4 \%$ of general practising dentists were rated as having a low level of TMD knowledge, $61.1 \%$ of general practising dentists were rated as having a relatively low level of TMD knowledge $30.5 \%$ of general practising dentists were rated as having a fair level of TMD knowledge. Moreover, $4.4 \%$ of specialists were rated as having a low level of TMD knowledge 54\% of specialists dentists were rated as having a relatively low level of TMD knowledge $40.4 \%$ of specialists were rated as having a fair level of TMD knowledge. $7 \%$ of specialists were rated as having a high level of TMD knowledge. The results of a similar study of Rafati H, regarding dentists' knowledge of TMD in Iran showed that general dental practitioners' knowledge of TMD and its related factors was good and acceptable. This finding is not in line with the results of our study. This difference may be due to the used questionnaire, which contains only questions regarding knowledge, not attitude and the practice, and the investigated group, which is only general practitioners and does not conclude experts and specialists: 400 general dentists were investigated. $13 \%$ were categorised as having a low level of knowledge while $50 \%$ had good and excellent level of knowledge of TMD. 10\% had low a level of awareness of TMD, and more than $60 \%$ were completely familiar with related factors. Compared to practising dentists, the TMD experts in this study had a higher level of knowledge of TMD in aetiology, signs and symptoms, and diagnosis domains. However, in the domain, the experts are almost in agreement with the practising dentists, which again can lead to the conclusion that the presumed ability to present a correct and effective treatment is not high enough among respondents. Rapidly growing concepts on temporomandibular disorders and their treatment can also be contributing factors to this issue for TMD problems. ${ }^{4}$

\section{CONCLUSION}

In spite of the TMD problems, the level of knowledge of TMD among the assessed group of general dental practitioners is less prevalent than Specialists. Certainly, more needs to be done to increase awareness about this condition, especially among GDPs. Yet diagnosis of these patients requires considerable time, which is rarely available in primary care. The dentists with no or least exposure to TMD problems need to update regularly. The majority of them are not willing to visit TMD patients, believing they did not have sufficient professional education on the subject, the aetiology, sign and symptoms, diagnosis and treatment of TMD. Hence, curriculum of the dental schools and continuous education programs need to be revised to ensure a proper practice in the diagnosis and treatment of TMD patients.

\section{REFERENCES}

1. Al-Riyami S. Temporomandibular joint disorders in patients with skeletal discrepancies. Doctoral thesis. Ucleastman dental institute for oral health sciences 2010 .

2. http://www.tmj.org.

3. Baharvand $\mathrm{M}$, Monfared $\mathrm{MS}$, Hamian $\mathrm{M}$, et al. Temporomandibular disorders: knowledge, attitude and practice among dentists in Tehran. Iran Journal of Dental Research, Dental Clinics, Dental Prospects 2010;4(3):904 .

4. Tegelberg A, Wenneberg B, List T. General practice dentists' knowledge of temporomandibular disorders in children and adolescents. Eur J Dent Educ 2007; 11(4): 216-21.

5. Friction JR, Hathaway K, Kroening R. TMJ and craniofacial pain diagnosis and management. All India Publishers 2006.

6. Le Resche L, Truelove EL, Dworkin SF. Temporomandibular disorders: a survey of dentists' knowledge and beliefs. J Am Dent Assoc 1993;124(5):904, 97-106.

7. Okeson JP. Management of temporomandibular disorders and occlusion. $5^{\text {th }}$ edn. St Louis: Mosby 2003. 